\title{
Experiment and Simulation Effects of Cyclic Pitch Control on Performance of Horizontal Axis Wind Turbine
}

\author{
Le Quang Sanga,b**, Takao Maedac, Yasunari Kamadac, and Qing'an $\mathrm{Li}^{\mathrm{c}}$ \\ ${ }^{a}$ Division of System Engineering, Mie University, 1577 Kurimamachiya-cho, Tsu, Mie 514-8507, Japan \\ ${ }^{b}$ Institute of Energy Science - Vietnam Academy of Science and Technology, 18 Hoang Quoc Viet, Cau Giay, Ha Noi, Vietnam \\ 'Division of Mechanical Engineering, Mie University, 1577 Kurimamachiya-cho, Tsu, Mie 514-8507, Japan
}

\begin{abstract}
Offshore wind is generally stronger and more consistent than wind on land. A large part of the offshore wind resource is however located in deep water, where floating wind turbines can harvest more energy. This paper describes a systematic experiment and a simulation analysis (FAST code) about the cyclic pitch control of blades. This work was performed to investigate performance fluctuation of a floating wind turbine utilizing cyclic pitch control. The experiment was carried out in an open wind tunnel with mainstream wind velocity of $10 \mathrm{~m} / \mathrm{s}$ with the front inflow wind and the oblique inflow wind conditions. A model wind turbine is two-bladed downwind wind turbine with diameter of $1.6 \mathrm{~m}$. Moment and force acts on the model wind turbine were measured by a six-component balance. Fluctuation of power coefficient and thrust coefficient was investigated in the cyclic pitch control. The model wind turbine and the experimental conditions were simulated by FAST code. The comparison of the experimental data and the simulation results of FAST code show that the power coefficient and thrust coefficient are in good agreement.
\end{abstract}

Keywords: Floating Offshore Wind Turbine, Aerodynamic Forces, Cyclic Pitch Control, FAST Code, Wind Tunnel Experiment.

Article History: Received February $11^{\text {st }} 2017$; Received in revised form April 29 th $^{\text {2017; }}$ Accepted June $2^{\text {nd }}$ 2017; Available online How to Cite This Article: Sang, L.Q., Maeda, T., Kamada, Y. and Li, Q. (2017) Experiment and simulation effect of cyclic pitch control on performance of horizontal axis wind turbine. International Journal of Renewable Energy Development, 6(2), 119-125. https://doi.org/10.14710/ijred.6.2.119-125

\section{Introduction}

Using of wind turbines has risen rapidly in recent years because of the potential that they offer for carbon free power generation. The wind power industry section is characterized not only by onshore development but also by offshore growth. Specifically, in 2015, offshore wind farm is one of the huge growth sources. This brought total offshore wind installed capacity to over $12 \mathrm{GW}$ (Global Wind Energy Council report 2015). It is need to exploit offshore wind resources which has been pushed into deeper waters, because the offshore wind has higher velocity, lower turbulence intensity and can also reduce visual and noise impacts (Liua et al. 2016). Presently, the wind turbine manufacturers are involved in producing wind turbines with higher rated power which means the rotor with larger diameter. Increasing the rotor diameters also introduces an asymmetric loading of the rotor blades (Hansen 2000 and Van Kuik el at. 2003).

However, the aerodynamic forces (such as wind and hydrodynamic force of the wave) have made quite an impact on the offshore wind farms (Tran and Kim 2015). Therefore, the control system becomes an important component in controlling these motions. Several controllers have been developed specifically for floating wind turbines. Some controllers were designed to avoid structural resonance. A research showed that an estimator-based controller was developed to avoid resonant pitch motions of the turbine wind and improve fatigue life. Results showed improvements in tower and blade fatigue life but the power output reduced (Nielsen et al. 2006). The others were used to regulate rotor speed and platform pitching (Namik and Stol 2011).

\footnotetext{
* Corresponding author: lequangsang@ies.vast.vn
} 
Citation: Sang, L.Q., Maeda, T., Kamada, Y., and Li, Q. (2017) Experiment and simulation effect of cyclic pitch control on performance of horizontal axis wind turbine. Int. Journal of Renewable Energy Development, 6(2), 119-125,https://doi.org/10.14710/1jred.6.2.119-125

$\mathrm{P}$ a g e | 120

In order to understand the effect of wind on performance of wind turbine, many researchers and universities have been studying with the different levels in wind tunnel or computational fluid dynamics (CFD) simulations. Jonkman and Sclavounos in 2006 presented a comprehensive simulation tool that can model the coupled dynamic response of offshore floating wind turbines (Jonkman and Sclavounos 2006). A linear frequency domain hydrodynamics technique was used to analyse a tension leg platform (TLP) design and a taut-leg spar-buoy design for a 1.5MW wind turbine (Lee 2005). This technique also used a similar process to analyse multiple TLP designs and a shallow-drafted barge (SDB) design for a 5-MW wind turbine (Wayman et al. 2006). However, in order to understand clearly the effect of cyclic pitch control on performance of the offshore wind turbine, this paper will show the experimental data and simulation results to estimate that effect.

The previous studies related to yaw control have primarily focused on increasing the power capture through improved yaw alignment such as in (Knud el at. 2015 and Gebraad el at. 2016). The large static yaw errors were observed on megawatt (MW) size onshore turbines that indicated a potential for increased power capture by improved yaw alignment (Mikkelsen et al. 2010 and Pedersen et al. 2008).

While the majority of offshore wind turbines today are upwind in configuration, there have been an increased number of downwind offshore wind turbines that were designed and tested in recent years. The blockage effect of the downwind turbine's nacelle accelerates and redirects the incoming flow into the rotor, resulting in up to $3 \%$ higher power for a downwind turbine compared to an upwind turbine (Frau el at. 2015). The downwind offshore wind turbine projects was performed in the industries and projects such as 2-B Energy (Miller 2015), the Fukushima FORWARD project (Fukushima Offshore Wind Consortium 2013 and 2014).

Thence, the paper will compare the experimental data with the simulation results by the FAST code. The objective of this study is to estimate the effect of the cyclic pitch control method on the power coefficient and thrust coefficient of the two-bladed downwind wind turbine in the two wind conditions: the front inflow and the oblique inflow wind. Moment and force acting on model wind turbine are measured by a six-component balance.

\section{Experimental Apparatus and Method}

\subsection{Experimental apparatus}

The experiment is performed in an open wind tunnel with an outlet diameter of $3.6 \mathrm{~m}$ and an air collector size of $4.5 \mathrm{~m} \times 4.5 \mathrm{~m}$ as shown in Figure 1 . The mainstream wind velocity can be adjusted in the range from 0 to $30 \mathrm{~m} / \mathrm{s}$. The uniformity flow reduced at the wind tunnel inlet of the test section is about $1.5 \%$ and the turbulence intensity is less than $0.5 \%$. This open wind tunnel is also depicted in previous papers (Maeda et al. 2014) (Li et al. 2016a) and (Li et al. 2016b).

A two-bladed downwind horizontal axis wind turbine (HAWT) model is used with a blade length of $\mathrm{R}=0.8 \mathrm{~m}$. The blade is an Avistar airfoil. The rotor rotational speed is adjusted by a variable speed generator. The rated rotational speed is $880 \mathrm{rpm}$ and it is possible to set up to a maximum of $1200 \mathrm{rpm}$.

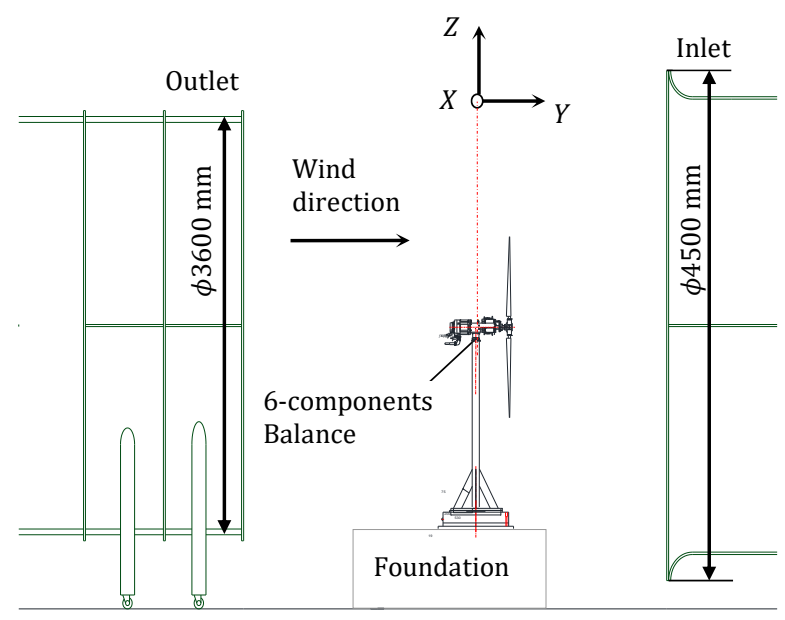

Fig. 1 Wind tunnel measurement section and test wind turbine

In order to measure the forces and moments applied to the entire wind turbine in the three directions of $x, y$ and $z$-axes, a six-component balance is used and can be measured simultaneously during the experimental process. The load force is calculated at the rotor center.

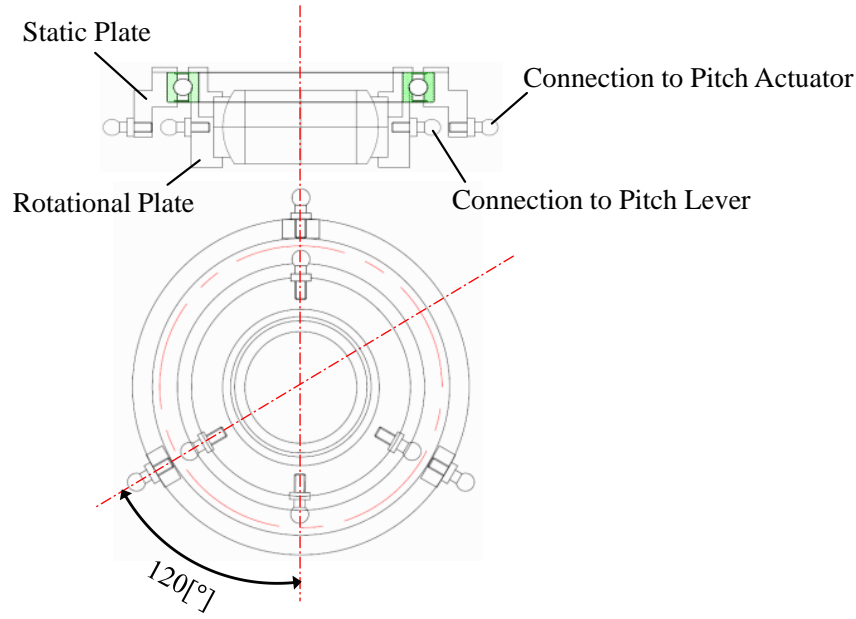

Fig. 2 Swash plate diagram

\subsection{Swash plate equipment}

The swash plate is used to change the pitch angle of the blade, which is shown in Figure 2. The swash plate consists of two discs: a non-rotating part and a 
rotating part, via a bearing. The swash plate is controlled by three pitch angle control actuators mounted on the nacelle.

The control points of the three actuators in the non-rotating part are located at the azimuth angles of $\psi=0^{\circ}, 120^{\circ}$ and $240^{\circ}$. The pitch angle change is calculated as follows:

$$
\theta(\psi)=a \cos (\psi-\xi)+b
$$

where:

- $\theta$ is the pitch angle,

- $\psi$ is the azimuth angle,

- $\quad a$ is the pitch angle variation amplitude,

- $b$ is the average pitch angle,

- $\quad \xi$ is the phase angle of the pitch angle $\theta$ with respect to the azimuth angle $\psi$,

\subsection{Simulation tool}

FAST (Fatigue, Aerodynamics, Structures and Turbulence) is a nonlinear time-domain simulation tool that is capable of modeling the coupled aerohydro-servo-elastic response of floating offshore systems. FAST was developed by the American National Renewable Energy Laboratory (NREL) and was certified by GL (Germanischer Lloyd), a German certification body. This code permits users to model the dynamic response of conventional horizontal-axis wind turbines with both two and three blades. Additional features have been added to the FAST code in recent years, which makes FAST an attractive code for calculating HAWT both onshore and offshore. As a significant capability, FAST can interact with other codes such as WAMIT (Lee and Newman 2004) (a powerful software for analyzing and calculating the wave load in offshore structures), and other utilities such as DLL (Dynamic Link Library) interface for Bladed (Jonkman and Buhl 2005).

FAST performs coupled analysis by AeroDyn which performs structural calculation and aerodynamic calculation. AeroDyn is an aerodynamic analysis module based on the Blade Elemental Momentum Theory. FAST has a limited number of structural degrees-of-freedom (DOFs) but can model most common wind turbine configurations and control scenarios. These DOFs can be enabled or locked through switches, permitting the user to easily increase or decrease the fidelity of the model (Jonkman and Sclavounos 2006).

\subsection{Experimental method}

The wind turbine performance and the steady pitch control experiment performed to estimate effect of the pitch angle control on performance of the wind turbine. The parameters considered such as the power coefficient, the thrust coefficient and the pitch angle. In this experiment, the wind condition divided into two types: the front inflow wind and the oblique inflow wind.

In the front inflow wind condition: For the wind turbine performance experiment, the tip speed ratio $\lambda$ changes from 0 to 11.1 . For the steady pitch control experiment, the generated dynamic force is measured when changing the pitch angle $\theta$ from $-2^{\circ}$ to $2^{\circ}$ at the mainstream wind velocity $U=10 \mathrm{~m} / \mathrm{s}$ and the optimum tip speed ratio $\lambda=7.4$.

In the oblique inflow wind condition, the same measurement is carried out in the oblique inflow wind condition by changing the yaw angle of $\varphi=-10^{\circ},-5^{\circ}, 0$, $+5^{\circ}$ and $+10^{\circ}$.

\subsection{Calculation method}

The aerodynamic efficiency of the model wind turbine is exhibited by the power coefficient and thrust coefficient. They are shown as follows:

$$
\begin{aligned}
C_{p} & =\frac{Q \omega}{0.5 \rho A U^{3}} \\
C_{\mathrm{T}} & =\frac{T}{0.5 \rho U^{2} A}
\end{aligned}
$$

The tip speed ratio is the ratio of the blade tip velocity at the mainstream wind velocity $U$ and is shown as follows:

$\lambda=\frac{R \omega}{U}$

where:

- $Q$ is the rotor torque,

- $T$ is the thrust force acting on the rotor face,

- $\omega$ is angular velocity of rotor,

- $\rho$ is the density of air,

- $A$ is the swept area of a wind turbine,

- $U$ is mainstream wind velocity,

- $R$ is rotor radius.

\section{Results and Discussion}

\subsection{Wind turbine performance experiment}

Figure 3 shows the power coefficient curves for the pitch angle change of the model wind turbine. Mainstream wind velocity is $U=10 \mathrm{~m} / \mathrm{s}$. The vertical axis presents the power coefficient $C_{\text {P. }}$. The horizontal axis is the tip speed ratio. From Figure 3, the maximum power coefficient decreases when the pitch angle increases or decreases from $\theta=0^{\circ}$. This is because the inflow angle to the blade element in the low tip speed ratio region is large, and in the case of the large pitch angle, the angle of attack becomes close to the optimum value and the power coefficient becomes high. On the contrary, the inflow angle in the high tip speed ratio region is small, and in the case of 
Citation: Sang, L.Q., Maeda, T., Kamada, Y., and Li, Q. (2017) Experiment and simulation effect of cyclic pitch control on performance of horizontal axis wind turbine. Int. Journal of Renewable Energy Development, 6(2), 119-125,https://doi.org/10.14710/1jred.6.2.119-125

$\mathrm{P}$ a g e | 122

the small pitch angle, the angle of attack is sufficient for lift generation, but the generated rotation direction component of the lift decreases and the power coefficient becomes low. The data are measured in this experiment. The maximum power coefficient is obtained at the pitch angle of $\theta=0^{\circ}$, and the tip speed ratio is $\lambda=7.4$. Therefore, for an optimum operation of the model wind turbine, the tip speed ratio is set to $\lambda$ $=7.4$ and the pitch angle is $\theta=0^{\circ}$.

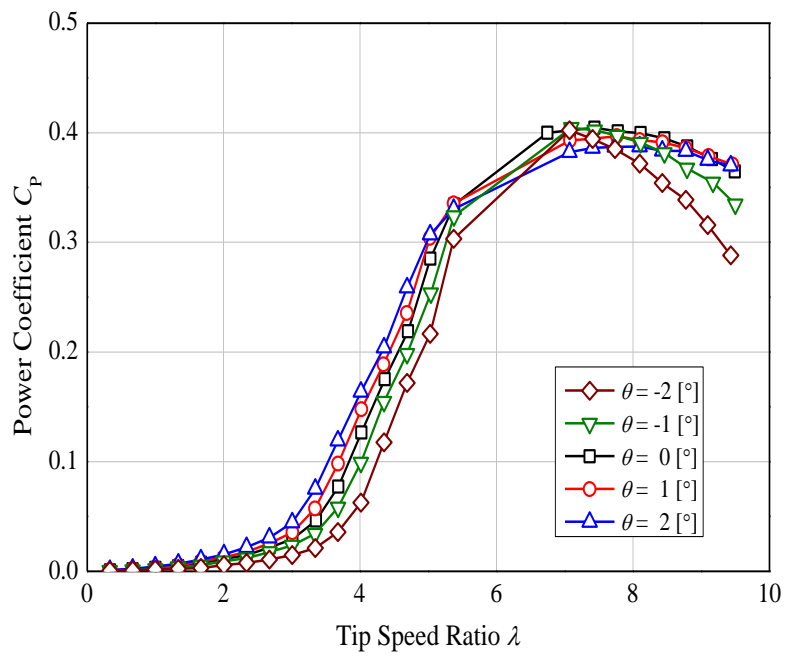

Fig. 3 Fluctuation of power coefficient at the pitch angle change

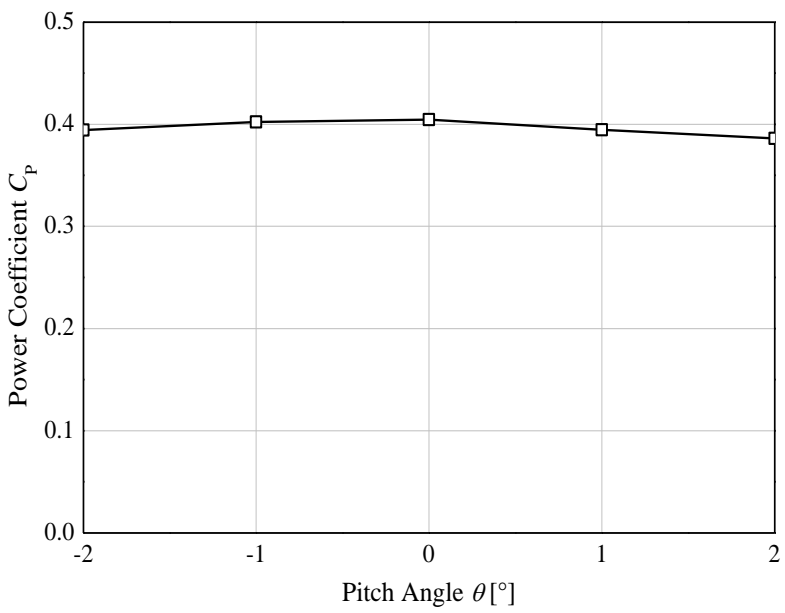

Fig. 4 Fluctuation of power coefficient at steady pitch control

The relationship between the power coefficient with the pitch angle in the steady pitch control of the model wind turbine is seen in Figure 4. The optimum operation tip speed ratio of the model wind turbine is $\lambda=7.4$, and the pitch angle is changed from $-2^{\circ}$ to $2^{\circ}$ with intervals of $1^{\circ}$. From Figure 4 , the optimum value of the pitch angle is $\theta=0^{\circ}$ and the maximum power coefficient is $C_{\mathrm{P}}=0.405$. The power coefficient also decreases when the pitch angle is adjusted out of the value of $0^{\circ}$.

\subsection{The oblique inflow wind condition}

In the wind turbine power performance experiment, the pitch angle and the mainstream inflow velocity are set in an oblique incoming wind condition. The tip speed ratio is changed. The power and thrust coefficient on the rotor surface of the model wind turbine are measured.

Figure 5 and 6 exhibit the power coefficient and the thrust coefficient curve for the yaw angle modification of the model wind turbine. The maximum power coefficient obtains $C_{\mathrm{P}}=0.405$ at the yaw angle of $\varphi=0^{\circ}$ as shown in Figure 5. The value of the maximum power coefficient decreases as the yaw angle increases or decreases. However, the value of the tip speed ratio indicates the maximum power coefficient is constant regardless of the yaw angle change. Here, the angle of attack is considered at the oblique incoming wind condition. It is assumed that the rotor blade rotation axis is inclined relative to the mainstream inflow velocity $U$ as seen in Equations 5 and 6 . The horizontal velocity component in the main rotor blade rotation plane is $U_{\mathrm{r}}$ and the axial velocity component is $U_{\mathrm{a}}$ :

$$
\begin{gathered}
U_{\mathrm{r}}=U \sin \varphi \\
U_{\mathrm{a}}=U \cos \varphi
\end{gathered}
$$

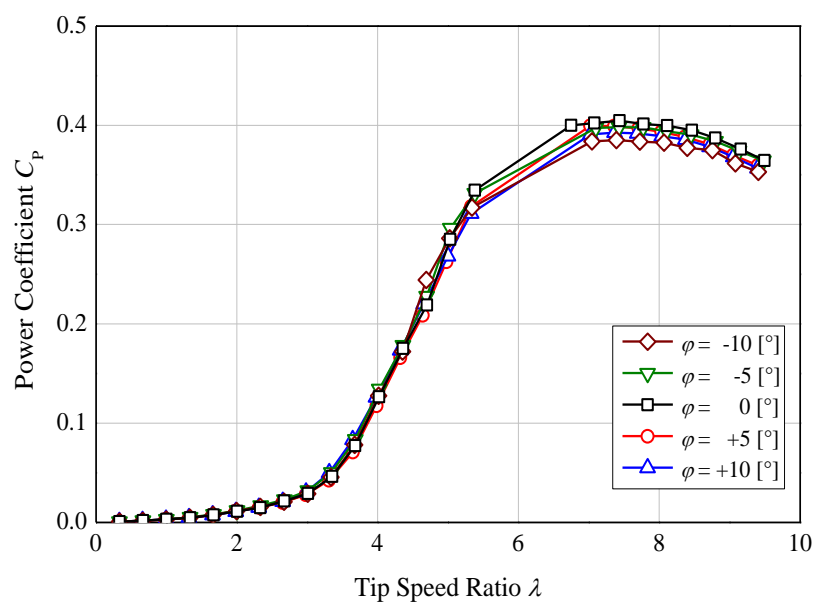

Fig. 5 Fluctuation of power coefficient responds to change of yaw angle $\varphi= \pm 10^{\circ}, \pm 5^{\circ}$ and $0^{\circ}$.

From Figure 6, the thrust coefficient $C_{\mathrm{T}}$ at each yaw angle increases monotonically when the tip speed ratio $\lambda$ increases. Due to the horizontal velocity component of the mainstream wind velocity occurring in the oblique inflow wind condition, the angle of attack periodically changes with one rotation of the rotor blades. The change of angle of attack increases when the yaw angle increases. Furthermore, the average value of the angle of attack decreases as the yaw angle increases. Therefore, as the yaw angle increases, the thrust coefficient decreases, and the gradient of the thrust coefficient with respect to the 
tip speed ratio becomes moderate. In addition, due to the influence of the flow field of the tower wake, it shows different directions depending on whether the yaw angle is positive or negative.

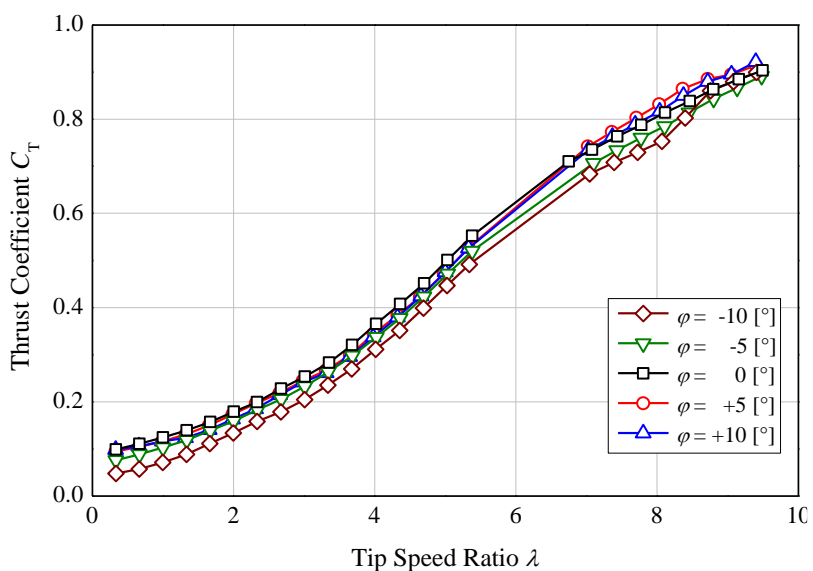

Fig. 6 Fluctuation of thrust coefficient responds to change of yaw angle $\varphi= \pm 10^{\circ}, \pm 5^{\circ}$ and $0^{\circ}$.

Figure 7 indicates the relationship between the power coefficient and the pitch angle change for the steady pitch control of the model wind turbine in the oblique inflow wind condition. The optimum operation tip speed ratio of the model wind turbine is $\lambda=7.4$. In the case of the yaw angle of $\varphi=0^{\circ}$, the pitch angle is changed from $-1^{\circ}$ to $1^{\circ}$ with intervals of $1^{\circ}$. When the yaw angle of $\varphi= \pm 5^{\circ}$ and $\pm 10^{\circ}$, the pitch angle is varied every $0.5^{\circ}$ from $-1^{\circ}$ to $1^{\circ}$. From the Figure 7 , the optimum value of the pitch angle is $\theta=0^{\circ}$ and the maximum power coefficient is $C_{\mathrm{P}}=0.405$. No significant change is seen in the power coefficient at yaw angle of $\varphi= \pm 5^{\circ}$ compared with the power coefficient of the yaw angle of $\varphi=0^{\circ}$. However, the power coefficient at the yaw angle of $\varphi= \pm 10^{\circ}$ becomes smaller as compared with the power coefficient of the yaw angle of $\varphi=0^{\circ}$. In addition, the power coefficient decreases from the optimum pitch angle of $\theta=0^{\circ}$ to an excessively small value in the oblique inflow wind condition.

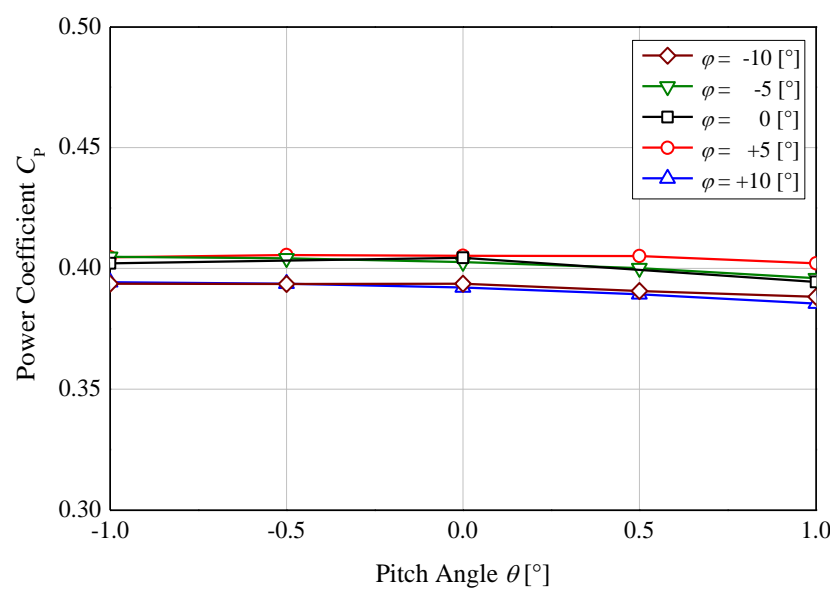

Fig. 7 Relationship between power coefficient and the blade pitch angle when the yaw angles are $\varphi= \pm 10^{\circ}, \pm 5^{\circ}$ and $0^{\circ}$.

\subsection{Simulation results and experiment}

The model wind turbine used in this experiment was simulated by FAST code. In order to understand clearly the effect of the cyclic pitch control on the power coefficient of the model wind turbine, the simulation results are compared with the experimental data.

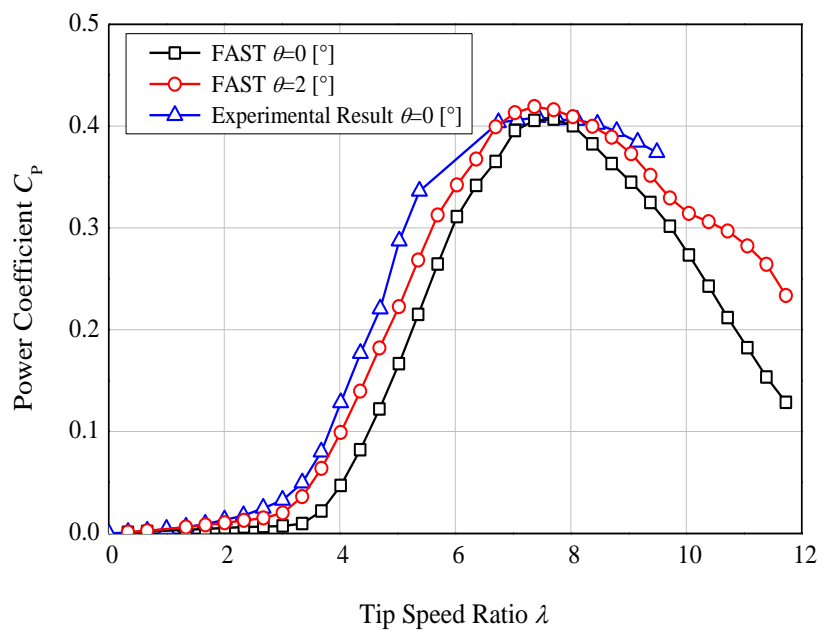

Fig. 8 Comparison of power coefficient of experimental data with simulation result in the front inflow wind condition

The experimental result that is used to compare with FAST analysis results is measured in items 3.1 and 3.2. This simulation analysis is carried out with two wind conditions: the front inflow wind and the oblique inflow wind condition. Therefore, the simulation analysis conditions of FAST are performed under the same experimental condition. The main parameters are filled in the FAST Primary file. The number of blades is 2 , the rotor radius is $0.8 \mathrm{~m}$, the blade root radius is $0.08 \mathrm{~m}$, and the hub height is $1.535 \mathrm{~m}$. In addition, the length and weight of the parts inside the nacelle are also input based on the design data. The power coefficient and the thrust coefficient of the model wind turbine are used to compare.

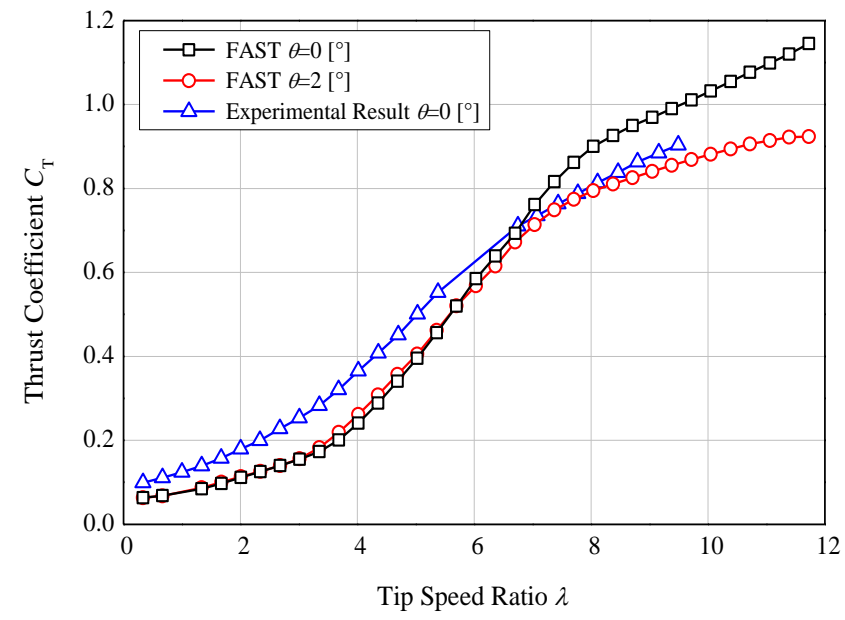

Fig. 9 Comparison of thrust coefficient of experimental data with simulation result in the front inflow wind condition 
Citation: Sang, L.Q., Maeda, T., Kamada, Y., and Li, Q. (2017) Experiment and simulation effect of cyclic pitch control on performance of horizontal axis wind turbine. Int. Journal of Renewable Energy Development, 6(2), 119-125,https://doi.org/10.14710/ijred.6.2.119-125

$\mathrm{P}$ a g e | 124

Figure 8 and 9 compare the simulation results of the power coefficient and the thrust coefficient with the experimental data in the front inflow wind condition. Comparison is made between the simulation analysis at the pitch angle of $\theta=0^{\circ}$ and $2^{\circ}$ and the experimental data of $\theta=0^{\circ}$. From Figure 8, for the pitch angle $\theta=0^{\circ}$, the maximum power coefficient in the simulation result is $C_{\mathrm{P}}=0.406$ at the tip speed ratio of $\lambda=7.7$, and for the pitch angle $\theta=2^{\circ}$ is $C_{\mathrm{P}}=0.419$ at $\lambda=7.4$. Maximum power coefficient of the model wind turbine in the experiment is $C_{\mathrm{P}}=$ 0.405 at $\lambda=7.4$. At the pitch angle $\theta=0^{\circ}$, there is difference between simulation analysis results and experimental data because the simulation is not possible to fully take into account the flow field caused by the separated flow on the blade surface in the simulated analysis. Therefore, the power coefficient of the simulation analysis results is smaller than the experimental data at low tip speed ratio. The power coefficient of the simulation result at the pitch angle $\theta$ $=2^{\circ}$ is higher than the experimental value at the optimum tip speed ratio. It is in good agreement in the low tip speed ratio and high tip speed ratio.

The comparison of the simulation analysis results of the thrust coefficient with the experimental value in the front inflow wind condition is shown in Figure 9. Similarly with the power coefficient, the simulation results of the thrust coefficient at the pitch angle of $\theta$ $=0^{\circ}$ and $2^{\circ}$ and the experimental value at the pitch angle $\theta=0^{\circ}$ is considered. In Figure 9, the thrust coefficient in the simulation result at the pitch angle of $\theta=0^{\circ}$ is $C_{\mathrm{T}}=0.817$, at the pitch angle of $\theta=2^{\circ}$ is $C_{\mathrm{T}}$ $=0.748$ in $\lambda=7.4$. The thrust coefficient of the model wind turbine in the experiment is $C_{\mathrm{T}}=0.763$ in $\lambda=$ 7.4. The thrust coefficient of the simulation analysis results is in good agreement with the experimental values in the vicinity of the optimum tip speed ratio. Therefore, it can be considered reasonable to predict the wind turbine performance in the front inflow wind by FAST, which was used in this study. The thrust coefficient at the pitch angle $\theta=2^{\circ}$ of the analysis result is in good agreement with the experimental value from the optimal tip speed ratio point and later.

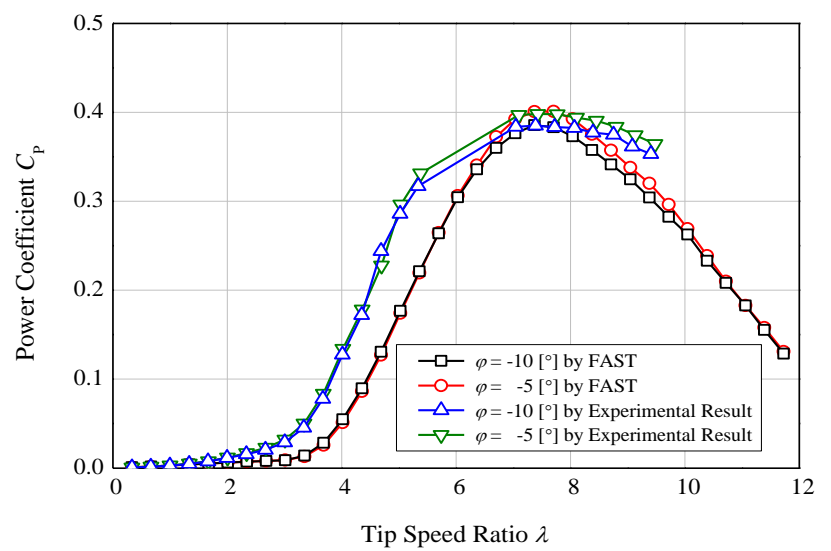

Fig. 10 Comparison of power coefficient of experimental data with simulation result in the diagonal flow wind condition
Figure 10 indicates the simulation results of the power coefficient of the wind turbine and the experimental values in the diagonal flow wind condition. From this figure, the maximum power coefficient at the yaw angle deviation of $\varphi=-5^{\circ}$ of the simulation analysis result is $C_{\mathrm{P}}=0.398$ in $\lambda=7.4$. The maximum power coefficient of the yaw angle deviation of $\varphi=-5^{\circ}$ in the experiment is $C_{\mathrm{P}}=0.401$ in $\lambda=7.4$. In addition, the maximum power coefficient of the yaw angle deviation of $\varphi=-10^{\circ}$ in the simulation analysis result is $C_{\mathrm{P}}=0.385$ in $\lambda=7.4$. The maximum power coefficient of the yaw angle deviation of $\varphi=-10^{\circ}$ in the experiment is $C_{\mathrm{P}}=0.385$ in $\lambda=7.4$. The simulation analysis results of the power coefficient are largely consistent with the experimental values in the vicinity of the optimum tip speed ratio.

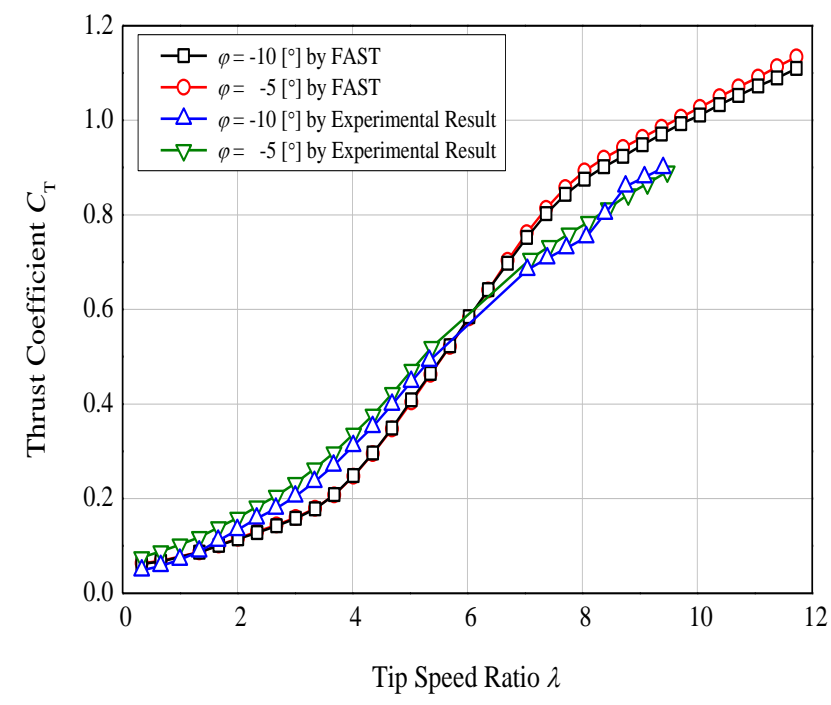

Fig. 11 Comparison of thrust coefficient of experimental data with simulation result in the diagonal flow wind condition

Figure 11 exhibits the simulation analysis results of the wind turbine thrust performance and the experimental data in the diagonal flow condition. The thrust coefficient of the simulation analysis result in the yaw angle deviation of $\varphi=-5^{\circ}$ at the optimum tip speed ratio is $C_{\mathrm{T}}=0.813$. The thrust coefficient of the model wind turbine of the experiment in the yaw angle deviation of $\varphi=-5^{\circ}$ at the optimum tip speed ratio is $C_{\mathrm{T}}=0.734$. In addition, the thrust coefficient of the simulation analysis result and the experimental data in yaw angle deviation of $\varphi=-10^{\circ}$ at the optimum tip speed ratio is $C_{\mathrm{T}}=0.802$ and $C_{\mathrm{T}}=0.708$, respectively. The simulated analysis results of the thrust coefficient are also largely consistent with the experimental values in the vicinity of the optimum tip speed ratio. In a similar way with in the front inflow wind condition, the wind turbine performance prediction in the diagonal flow wind condition by FAST, which was used in this simulation, can be considered reasonable. 


\section{Conclusion}

In this study, the cyclic pitch control method of the FOWT was presented in the wind tunnel experiments. These experimental experiments were compared with the simulation results by FAST code. In the experiment, the power coefficient and thrust coefficient characteristics during the pitch angle control process in the front and diagonal inflow wind conditions were evaluated. Numerical analysis was carried out using aerodynamic elasticity simulation (FAST code), and the validity of numerical simulation was verified. The main results of this research are as follows.

- The validity of the power performance and the thrust performance of the model wind turbine can be verified in the front inflow wind and diagonal inflow wind condition.

- The FAST code could show the possibility of conceptual design of large wind turbine by cyclic pitch control with simple calculation under quasi steady state.

\section{Acknowledgments}

This experiment was performed in Mie UniversityFluid Engineering Laboratory for Energy and Environment in Japan. We would like to thank all those who have reviewed and contributed to this paper for their valuable assistance.

\section{References}

Frau E, Kress C, Chokani N and Abhari R S. (2015) Comparison of performance and unsteady loads of multimegawatt downwind and upwind turbines. J Sol Energ Eng. 137(4), 041004.

Fukushima Offshore Wind Consortium. (2013) Fukushima floating offshore wind farm demonstration project (Fukushima FORWARD). Tokyo, Japan, Pamphlet.

Fukushima Offshore Wind Consortium. (2014) Fukushima floating offshore wind farm demonstration project (Fukushima FORWARD)-Construction of Phase I Pamphlet.

Gebraad P M O, Teeuwisse F W, van Wingerden J W, Fleming P A, Ruben S D, Marden J R and Pao L Y. (2016) Wind plant power op-timization through yaw control using a parametric model for wake effects - a CFD simulation study. Wind Energy. 19 (1), 95-114.

Global Wind Energy Council. (2015) Global Wind Report Annual Market Update.

Hansen. (2000) Aerodynamics of Wind Turbines. James \& James.

Jonkman J.M. and Sclavounos P.D. (2006) Development of Fully Coupled Aeroelastic and Hydrodynamic Models for Offshore Wind Turbines. 2006 ASME Wind Energy Symposium Reno, Nevada. NREL/CP-500-39066

Jonkman J.M. and Buhl Jr.M.L. (2005) FAST User's Guide. Technical Report. NREL/EL-500-38230.
Knud A. Kragh and Morten H. Hansen. (2015) Potential of power gain with improved yaw alignment. Wind Energy. 18 (6), 979-989.

Mikkelsen T, Hansen K, Angelou N, Sjöholm M, Harris M, Hadley P, Scullion R, Ellis G, Vives G. (2010) Lidar measurements from a rotating spinner. In Proceedings of EWEC2010, Warzaw.

Miller B. 2-B (2015) Energy to launch two-blade 6 MW offshore turbine in 2015. Windpower offshore. Available online: http://www.windpoweroffshore.com/article/1226740/2-benergy-launch-two-blade-6mw-offshore-turbine-2015, 2014 [accessed 15.12.16].

Lee K. H., (2005) Responses of Floating Wind Turbines to Wind and Wave Excitation, M.S. Dissertation, Department of Ocean Engineering, Massachusetts Institute of Technology, Cambridge, MA, USA.

Lee K. H. and Newman J. N. (2004) WAMIT® User Manual, Versions 6.2, 6.2PC, 6.2S, 6.2S-PC. WAMIT, Inc., Chestnut Hill, Massachusetts.

Li Q, Kamada Y, Maeda T, Murata J, Nishida Y. (2016a) Effect of turbulence on power performance of a Horizontal Axis Wind Turbine in yawed and no-yawed flow conditions. Energy. 109, 703-711.

Li Q, Murata J, Endo M, Maeda T, Kamada Y. (2016b) Experimental and numerical investigation of the effect of turbulent inflow on a Horizontal Axis Wind Turbine (Part I: Power performance). Energy. 113, 713-722.

Liua Y, Sunwei Lia, Qian Yia, and Daoyi Chena (2016) Developments in semi-submersible floating foundations supporting wind turbines: A comprehensive review. Renewable and Sustainable Energy Reviews. 60, 433-449.

Maeda T, Kamada Y and Murata J. (2014) LDV measurement of boundary layer on rotating blade surface in wind tunnel. Journal of Physics: Conference Series. IOP Publishing. 555(1) 012057.

Namik H., Stol K. (2011) Performance analysis of individual blade pitch control of offshore wind turbines on two floating platforms. Mechatronics, 21(4), 691-703.

Nielsen FG, Hanson TD, Skaare B. (2006) Integrated dynamic analysis of floating offshore wind turbines. Proceedings of the 25th International Conference on Offshore Mechanics and Arctic Engineering, Hamburg. 671-679.

Pedersen T F, Vita L, Sørensen N N and Enevoldsen P. (2008) Operational experiences with a spinner anemometer on a MW size wind turbine. In Proceedings of EWEC2008, Brussels.

Tran T T and Kim D H. (2015) The platform pitching motion of floating offshore wind turbine: A preliminary unsteady aerodynamic analysis. Journal of Wind Engineering and Industrial Aerodynamics. 142, 65-81.

Van Kuik G, van Holten T, Verhaegen M and Dijkstra S. (2003) Smart dynamic rotor control of large offshore wind turbines. Report, Technologiestichting STW.

Wayman, E. N., Sclavounos, P. D., Butterfield, S., Jonkman, J., and Musial, W. (2006) Coupled Dynamic Modeling of Floating Wind Turbine Systems. 2006 Offshore Technology Conference, 1-4 May 2006, Houston, TX [CDROM], Richardson, TX: Offshore Technology Conference, OTC 18287, NREL/CP-500-39481, Golden, CO: National Renewable Energy Laboratory. 